\title{
Correction to: Scientific integrity and the IAAF testosterone regulations
}

\author{
Roger Pielke Jr. ${ }^{1}$ (1) $\cdot$ Ross $^{\text {Tucker }}{ }^{2} \cdot$ Erik Boye $^{3}$
}

Published online: 18 April 2019

(c) T.M.C. Asser Instituut 2019

\section{Correction to: The International Sports Law Journal https://doi.org/10.1007/s40318-019-00143-w}

Dear Readers,

In this article, some minor mistakes have accidentally crept in. These are listed below:

1. In Table 5, BG17 and BHKE18 should change positions.

2. The same it true for Fig. 2, which is attached as corrected.

3. Also, in the bullet points below the figure, please replace the first four bullet points with the following:

- For 3 of 11 running events, the performance difference between the highest and lowest tertiles decreased from BG17 to BHKE18, including in 1 of 4 of the regulated events;

- In three events, the performance difference changed from negative (high $\mathrm{T}$ slower than low $\mathrm{T}$ ) to positive (high $\mathrm{T}$ faster than low T);

- In BHKE18, the low T tertile is faster than the high $T$ tertile in 3 of 11 events, compared to 6 of 11 events in BG17.

- In the four regulated events, the average difference in times was increased by $0.4 \%$ in absolute terms (i.e. from 1.6 to $2.0 \%$ ), and 3 of 4 meets the BHKE18 standard for statistical significance (BG17 reported 1 of 4$)$.
The original article can be found online at https://doi.org/10.1007/ s40318-019-00143-w.

\footnotetext{
Roger Pielke Jr. pielke@ colorado.edu

1 University of Colorado Boulder, Boulder, USA

2 University of Cape Town, Cape Town, South Africa

3 Oslo University Hospital, Oslo, Norway
} 
Performance difference between highest and lowest testosterone tertiles

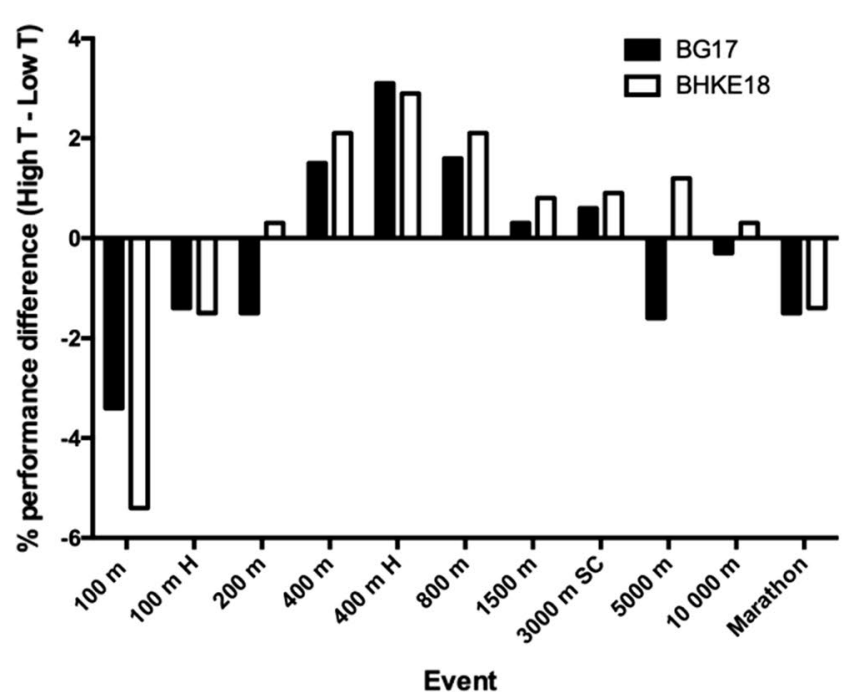

Percentage point improvement change in High vs Low $T$ performance differences after reanalysis

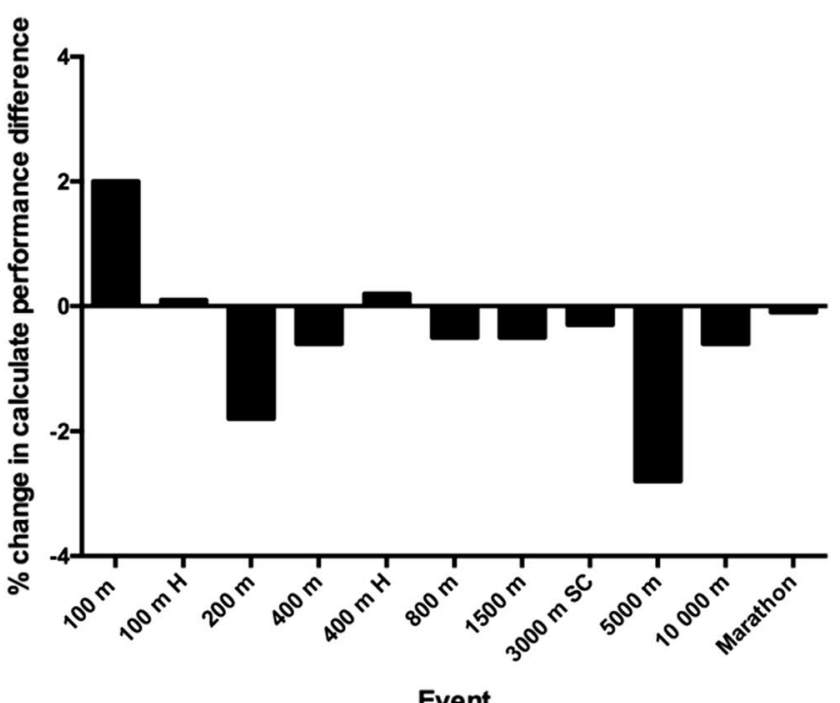

Event

Fig. 2 Performance differences between high and low testosterone tertiles (left panel) and change in difference between BG17 and BHKE18 (right panel)

None of these changes alter our analysis or conclusions, as the key point in this section was the magnitude of differences between the two studies, not the relative accuracy of one study over the other.

Nonetheless, we regret the errors and apologize.
Publisher's Note Springer Nature remains neutral with regard to jurisdictional claims in published maps and institutional affiliations. 